\title{
EL NO MÉTODO ZAPATISTA
}

\author{
Ana Lilia Félix Pichardo
}

\author{
¿Tú lo sabes cómo es su modo \\ del pinche capitalismo cabezón? \\ Bueno, mira, te lo voy a dar la plática política. \\ Resulta que la pinche sistema no te muerde \\ sólo por un lado sino que \\ onde quiera te está chingando. \\ Todo lo muerde la pinche sistema, \\ todo se lo zampa y si ya se engordó mucho, \\ pues lo gomita, y de vuelta con su tragadera. \\ Subcomandante Galeano
}

Niña defensa zapatista es, quien junto con Einstein, el caballo Choco, Marx, Sherlock Holmes, Eduardo Galeano, el Gato-perro y muchos otros personajes ilustres, desfila por las páginas de este libro; repartiendo su tiempo entre el futbol y la destrucción del muro, mientras nos cuenta cómo se vislumbra la tormenta desde aquel rincón del mundo y reta a preguntarnos qué signos tenemos nosotros del gran diluvio y cómo esperamos estar preparados para los fuertes vientos y las grandes aguas que se avecinan. Tal vez nosotros, desde cualquier espacio de nuestro cómodo sillón donde estemos acurrucados, leyendo las peripecias del Gato-perro y del Pedrito, ni siquiera suponíamos que una tormenta se dibujaba en el horizonte, quizá nosotros, víctimas del síndrome del vigía, no queríamos saber sobre la crisis del sistema capitalista que, como la caída de una gran muralla (en caso de que sea la crisis terminal del capitalismo), causará desgracias con su sistemático derrumbe. Pero ahí estamos ya, leyendo que algo grande y más destructivo que nunca está por venir, parece una profecía anunciando la llegada de un monstruo de mil cabezas, $y$, por supuesto, nosotros posmodernos desacralizadores del mundo y sus mitos, nos mantenemos escépticos, pero continuamos ahí y damos vuelta a la siguiente página. 
En la mayor complejidad que las palabras sencillas pueden guardar, la voz colectiva zapatista recorre los pasos de un método, el cual siguieron las comunidades para llegar a la conclusión de que está cabrón. Porque seremos, si no es que ya lo somos, testigos y parte de una de las peores depresiones que ha tenido el sistema desde su nacimiento. Y en esta guerra emprendida por la hidra contra la humanidad, pero también contra su propia naturaleza autodestructiva, habrá que estar preparados para salvaguardar el tiempo, la memoria, la humanidad, la dignidad y la vida. Por eso la preocupación por lo que viene es mayúscula, para lo que tendremos que estar preparados como colectivo que somos. Y bueno, pues en el cómo está el dónde, porque en el limbo de la barbarie y la desesperanza, cuya venta en el mercado, como producto milagroso, está a la alza, las zapatistas, los zapatistas, nos sugieren la descomposición del monstruo neoliberal para conocer cada una de sus partes, su nacimiento, su crecimiento y contribuir así a su posible muerte.

De manera crítica las comunidades se entienden como parte de un proceso histórico y se explican a sí mismas bajo los principios de la ciencia de la historia, reivindican la teoría política-económica-sociológica como herramienta fundamental y necesaria para el conocimiento de la génesis y evolución del sistema. Mas se mantienen reaciamente firmes frente a los falsos teóricos, que han recluido a la ciencia en el dogmatismo más puritano y obsoleto, desconfiados de los grupos de pseudocientíficos sociales ( $y$ naturales), que tan sólo contribuyen a endurecer las paredes de la burbuja que los contiene porque han hecho, también, de la ciencia un negocio y un lugar aséptico, agradable, seguro, donde las heces de la hidra pierden su olor y hasta se convierten en materia de «análisis» para su posterior engullimiento. Las zapatistas, los zapatistas, nos dicen claramente que sin teoría no hay práctica y viceversa: «tenemos la necesidad de una ciencia de la lucha. Sin la ciencia, espontáneamente tomaremos lo que tengamos a la mano para proveernos de una explicación, es decir, de un consuelo» (sci Galeano, 2015: 291). ¿Cómo llegaron a este punto? Experimentando para volver a incidir con la práctica en la realidad y 
teorizando sobre esa praxis para volver y mejorar el método de lucha, de transformación.

La rebeldía y la resistencia son los instrumentos que al método experimental zapatista lo hacen muy otro. Puesto que le han permitido hacer análisis exhaustivos de su realidad, de los factores externos a su práctica, de las equivocaciones, para poder así autoevaluar los pasos que daban, pensar en colectivo cuáles eran las mejores vías para seguir andando y cuándo era necesario retroceder o abrir nuevas brechas que permitieran caminar mejor a la dignidad: «Nos ha dado la libertad para crear, inventar, imaginar de cómo trabajar mejor nuestro gobernar para tener una mejor vida, y eso es lo que nos está ayudando de ir descubriendo de cómo mejorar el gobernar o su trabajo de nuestros gobiernos autónomos» (SCI Moisés, 2015: 158).

Por tanto, su palabra nos comparte cómo ha sido su vivir de lucha contra las mil cabezas del legendario ser, que pareciera también un ¿fénix?, no sé. Y es que tal vez lo conocemos tan poco, que ni siquiera podemos decir cuál es su más acertada analogía mítica, porque faltaría ver cómo será su muerte, cuál la espada que la desollará y quiénes empuñarán el arma. La observación y análisis del fenómeno son los primeros pasos...

He aquí la importancia de hacer y conocer la teoría, que nos hace evidente la palabra zapatista, el alcance de conocer tantos espejos como sea posible, para encontrar el reflejo de la propia práctica y analizarla de una mejor manera. Porque, también, en ese juego de espejos logrado por las resistencias mundiales, vive la visión amplificada de cada una de las cabezas del monstruo capitalista, y es posible ver cómo es su reacción ante las diferentes luchas y dignidades, que la enfrentan con el rostro cubierto o desenmascarados. La genealogía de la lucha de la organización zapatista nos da muestra de ello porque en su mirar hacia atrás han descubierto que nada surge de la nada, que para caminar preguntando ha sido fundamental en colectivo cuestionar: si como se ha venido golpeando al muro a través de los años ha sido la mejor manera para derribarlo, esto último da cuenta de cómo se puede mejorar la 
técnica para seguir derribando los grandes pilares que sostienen al sistema-muro-hidra.

El lenguaje del libro nos permite un acercamiento ontológico de la organización zapatista. La voz del subomandante insurgente (SCI) Moisés nos traslada a la comprensión de una visión de mundo muy particular, uno donde en realidad sí caben muchos mundos. La sintaxis del español usado por los compas no es un error, es una variante de la lengua, que habla en y de sí misma, como un metalenguaje que nos dice más de lo que queremos escuchar. Porque acostumbrados hemos sido a cerrar nuestros oídos y ojos a toda forma de «nuestra» lengua que sea diferente y, pues como ellos, su palabra, su pensamiento, su acción, son muy su modo. Porque escuchar o leer de las compañeras, y los compañeros, un español fronterizo con el tzotzil, el tzeltal, el chol o el tojolabal, también nos connota una guerra invisible, de la cual no somos testigos o siquiera capaces de imaginar: es la resistencia feroz que libran las lenguas originarias porque sus hablantes sigan contando y cantando a través de ellas; porque el neoliberalismo nada sabe de palabras mágicas, sanadoras de dolores; palabras flotantes en la selva y el bosque; palabras que hacen del sonido de las balas un son y danzarinas corren al ritmo de marimbas imaginarias; palabras que abrigan a los combatientes y les susurran al oído que no se rindan.

Por eso la importancia de seguir taladrando el muro, o pateándolo siquiera, porque la resistencia es por la vida y todas las expresiones humanas que el capital mercantiliza o destruye cuando éstas no le generan ganancias. Leer este libro es decodificar el cómo de la lucha zapatista en sus dos vertientes: en forma y contenido, a través de las palabras que articulan y narran la resistencia zapatista en forma de una niña, reclutando jugadores para una partida de futbol, o las travesuras del Gatoperro; pero también en voz de las comandantas Miriam, Rosalinda y Dalia, que narran la genealogía y crecimiento de su lucha como mujeres zapatistas. Son ellas quienes resignifican conceptos de igualdad de género y justicia, a través de su variante lingüística, rescatando de esta manera a las palabras, que han sido condenadas a los lugares comunes por la 
banalización de los falsos discursos políticos y progresistas, que se pronuncian día con día; y al mismo tiempo nos abren una ventana de la memoria de las comunidades, a la que podemos tener acceso y observar detenidamente cómo vivían las mujeres antes y después de la organización.

Porque al igual que de la praxis, el pensamiento y la palabra zapatista, la columna vertebral de este libro es la lucha de las mujeres, que está no únicamente en la narrativa que hacen ellas mismas de esa emancipación que comenzó mucho antes de 1994, sino de igual manera se hace presente en la discursividad del sci Moy y Galeano. Porque como el capítulo «La visión de los vencidos» lo hace patente, la lucha de las compañeras representó un batallar interno con el que se favorecieron todos, la organización se nutrió de la resistencia de las compañeras por construirse como entes políticos y colectivos dentro de las comunidades, dándole así sustento práctico a las palabras y a su teoría de lucha feminista, claro, otro feminismo.

Hoy la realidad ha rebasado un tanto la memoria de cómo se vivía antes del levantamiento armado y de la edificación de la autonomía en las comunidades. Como lo cuentan las compañeras de más edad, las niñas y jovencitas ya han nacido zapatistas y nada saben de la vida en las haciendas y de la condición de las mujeres en aquellos tiempos. Las problemáticas se han ido transformando, los retos son nuevos ahora que se resiste por conservar lo alcanzado, gracias a la lucha permanente contra el sistema y sus rostros multiformes. Sin embargo, dentro de la lucha que se gestó por más de 500 años, está la germinación de una resistencia más joven, la de las niñas, mujeres y ancianas, que junto con sus compañeros varones, buscan la reconfiguración simbólica de lo que es ser mujer, indígena, y además en resistencia.

El libro nos hace un recuento sobre la lucha desde antes de 1994 y por supuesto del alzamiento armado y lo que pasó después de la guerra, en esa genealogía es fundamental la lucha de las mujeres: su participación plena en el respaldo a los insurgentes desde los pueblos y después como agentes activos, como paridoras de la autonomía. Fueron ellas quienes impulsaron la ley contra el alcohol para disminuir la violencia doméstica y también mantuvieron una postura crítica sobre 
los avances en la convivencia pública y privada entre hombres y mujeres, pues «como lo trataron con el patrón los hombres, como que traen arrastrando malas ideas también los hombres, y aplica dentro de la casa como el patroncito de la casa. No es cierto que se liberó las mujeres sino que ya son los hombres que fueron el patroncito de la casa» (Comandanta Miriam, 2015: 113). Son ellas quienes ahora deciden con quién y cuándo casarse, cuántos hijos quieren tener, deciden sobre su cuerpo y su vida, desterrando así una de las costumbres más arraigadas a la cultura falocéntrica de los pueblos indígenas, que sustentaba la cosificación de las mujeres, por lo que eran tratadas como mercancía por sus padres y maridos.

Nos explican lo difícil que ha sido vencer al machismo desde el interior de la organización, la permanente lucha porque los hombres asimilen los nuevos roles de ellas. Pues han pasado de la vida completamente privada al espacio público-colectivo, para incidir en el quehacer político de los pueblos: "poco a poco fuimos perdiendo el miedo y la vergüenza, porque ya entendemos que tiene el derecho de participar en todas áreas de trabajo. Después nos dimos cuenta para hacer una revolución no sólo los hombres, tiene que hacer entre hombres y mujeres» (Comandanta Rosalinda, 2015: 117).

La vida en las comunidades gira en torno al colectivo y las actividades de la propia organización: el trabajo, las fiestas, las asambleas, las clases, la lucha. El zapatismo es la comprensión del yo en tanto el otro, no hay una renuncia del individuo en tanto que se le encuentra en el todo de la colectividad y ahí se reconocen todos como parte consustancial y dinámica. La familia como institución social, forzosamente, se vio inmersa en esta revolución y por tanto de alguna manera se han visto superadas las ideas conservacionistas del sistema económico hegemónico y patriarcal. Quizá por ello las mujeres zapatistas deciden vivir en pareja, porque es el núcleo primario para poder estar en comunidad; sin embargo, es ahí donde son palpables las grandes transformaciones que han empujado las zapatistas junto con sus compañeros rebeldes: 
La lucha de las mujeres indígenas busca incorporar a los varones. No se puede concebir como una lucha de mujeres contra o al margen de los hombres. Aunque se expresa como un reclamo y una rebeldía contra situaciones de dominación y sujeción de las mujeres, esa lucha existe a la par, es decir, que está subsumida en, y encapsulada, por, la certeza cosmológica y filosófica de la complementariedad y conjunción con el varón (Marcos, 2013: 24).

Porque, dice el sci Galeano, el zapatismo y toda nuestra lucha ha sido por la posibilidad de decidir. Los y las que vendrán claro está que podrán hacer las cosas según su modo, rompiendo todo esquema, incluso los construidos dentro de la autonomía. El pensamiento de los compas sugiere un antidogmatismo teórico y práctico en todos los sentidos y niveles de la colectividad. Por ello es que este libro no es un manual para convertirse al zapatismo, ni una guía práctica para derribar el muro y degollar a la hidra. Es más bien un así nosotros lo vemos y asi le hemos hecho, es una pregunta lanzada al aire esperando respuestas, muchas; es un reto y una mano de solidaridad tendida esperando quien la estreche desde cualquier lado del mundo; es y puede ser muchas cosas, usted puede encontrarle y leerlo como quiera: desde el principio, desde el final, de en medio. Y quizá se sienta contagiado para seguir conociendo cómo es que está armado el capitalismo, y sentirse preocupado por tomar turno e ir a darle martillazos, librazos, patadas, balonazos, golpes, cabezazos al muro.

Ponlo atención a lo que te voy a decir. Resulta que el Pedrito, ¿Lo conoces al Pedrito? No, ¿Verdad? Bueno el Pedrito es muy tarugo, pero así son los hombres, qué le vamos a hacer, ni modos. Bueno, entonces está el muro, ¿lo conoces el muro? Es como una piedrota que está así larga y alta [... [;] bueno, pues nuestro trabajo como mujeres zapatistas que somos es hoyarlo la piedrota. Claro, lo dejamos que también participen los hombres para que lo entiendan la lucha también. Aunque luego pues, ¿̇cómo te diré?, pues les cuesta, batallan pues. Son hombres pues... 


\section{BIBLIOGRAFÍA}

Comandanta Miriam (2015), «La lucha como mujeres zapatistas que somos I», en Vv.AA., El pensamiento crítico frente a la bidra capitalista I, México, autoedición.

Comandanta Rosalinda (2015), «La lucha como mujeres que somos II», vv.AA., op. cit.

Marcos, Sylvia (2013), Mujeres, indígenas, rebeldes, zapatistas, México, Eón.

SCI Galeano (2015), «Hacia la genealogía de la hidra», en vV.AA., op. cit.

SCI Moisés (2015), «Resistencia y rebeldía zapatistas II», VV.AA., op. cit. 